\title{
Matrix Metalloproteinase-9 Promoter Polymorphism in Primary Spontaneous Pneumothorax
}

\author{
Amal Ahmad Baalash ${ }^{1,2}$ and Bedir Mohamed Ibrahim ${ }^{3,4}$ \\ 1. Medical Biochemistry Department, Faculty of Medicine, Tanta University, Tanta, Egypt \\ 2. Basic Medical Sciences Department, King Fahad Medical City Faculty of Medicine, King Saud Bin Abdulaziz University for \\ Health Sciences, Riyadh, Saudi Arabia \\ 3. Cardiothoracic Surgery Department, Faculty of Medicine, Tanta University, Tanta, Egypt \\ 4. Catdiothoracic Surgery Department, Al Eiman Hospital, Riyadh, Saudi Arabia
}

\begin{abstract}
Primary spontaneous pneumothorax (PSP) is a common clinical problem occurring in apparently healthy subjects. However emphysema like changes (ELC) in patients with (PSP) has been demonstrated, which is associated with the degradation of extracellular matrix (ECM). MMP-9 has been proposed to play a role in the development of emphysema and is involved in the digestion of (ECM). Among several polymorphic changes reported in MMP-9 regulatory region, the C-1562T polymorphism increases its promoter activity. Aim of the work: To test the hypothesis that the MMP-9 C-1562T polymorphism has a role in the occurrence of PSP. Subjects and Methods: MMP-9 (C-1562T) genotypes of 104 PSP patients and 97 healthy subjects (control) were determined by the polymerase chain reaction, followed by a restriction fragment length polymorphism analysis. Results: This study showed that the genotype frequency for MMP-9 $1562 \mathrm{C}>\mathrm{T}$ differed significantly between healthy individuals and PSP patients, with higher T allele in MMP-9 promoter in PSP patients, and the $\mathrm{C} / \mathrm{T}+\mathrm{T} / \mathrm{T}$ genotypes significantly modified the risk of developing PSP, and were associated with increased risk for PSP. Conclusion: MMP-9-1562C/T genotype may be a potentially indicative factor for susceptibility to PSP, that is, genotypes with the T allele significantly increase the risk of development of PSP.
\end{abstract}

Key words: Primary spontaneous pneumothorax, MMP-9, promoter polymorphism.

\section{Introduction}

Spontaneous pneumothorax (SP) is defined as the presence of air in the pleural cavity. It is divided into primary SP (PSP) and secondary SP (SSP). SSP is associated with underlying lung diseases such as cystic fibrosis, chronic obstructive pulmonary disease (COPD), AIDS, etc. [1] while the so-called primary spontaneous pneumothorax is said to occur without obvious predisposing factors or trauma and is seen most frequently in young men, particularly those who are tall and asthenic and have long, narrow chests [2]. PSP remains a significant health problem, with an annual incidence of 18-28 pLer 100,000 populations in males and 1.2-6.0 per 100,000 populations in females [3].

Corresponding author: Amal Ahmad Baalash, associate professor, research field: medical biochemistry. E-mail: amalbaalash@hotmail.com.
Individuals with a (PSP) have no obvious lung disease, but preoperative computed tomography (CT) scans or intraoperative inspection generally reveal the presence of small subpleural blebs of the lung [1, 4]. Several studies have shown blebs and bullae in almost all patients during thoracotomy or sternotomy, and they have demonstrated blebs and bullae on the contralateral side in $79-96 \%$ of the patients with unilateral (PSP) $[5,6]$.

Blebs and bullae are designated as emphysema-like changes (ELCs). Several theories exist regarding the development of ELCs in patients with primary spontaneous pneumothorax. As in centriacinar emphysema, the formation of ELCs in primary spontaneous pneumothorax is associated with the degradation of extracellular matrix fibers caused by the disruption of the balance between matrix 
metalloproteinases (MMPs) and their endogenous inhibitors, which is called the protease/antiprotease imbalance [7,8].

The family of (MMPs) is a protein family of zinc-dependent endopeptidases. They are mainly involved in extracellular matrix (ECM) cleavage, MMPs have a much wider substrate repertoire, and their specific processing of bioactive molecules is their most important in vivo role [9].

MMP-9, has been proposed to play a role in the development of emphysema and is involved in the digestion of extracellular matrix components such as gelatin, collagens (IV, V, X I, XVII), and elastin [10]. The human MMP-9 gene is located on chromosome 20q11.1-13.1. Among several polymorphic changes reported in the regulatory region $[11,12]$, the $\mathrm{C}-1562 \mathrm{~T}$ polymorphism increases the promoter activity of MMP-9 [13, 14]. This polymorphism was shown to have a possible role in development of many diseases, including emphysema and COPD [15-18].

Based on the hypothesis that the development of ELC and the occurrence of pneumothorax may be related to differences in genes involved in extracellular matrix degradation, MMP-9 C-1562T polymorphism was compared in PSP patients and matched healthy volunteers.

\section{Subjects and Methods}

The study was designed as a case-control study. A total of 201 participants were recruited from August 2012 to December 2014 at Al-Eiman hospital in Riyadh, Saudi Arabia. The study comprised 104 patients suffered (PSP) and 97 healthy volunteers matched to patients based on ethnicity (all patients and volunteers were Middle Eastern Arabs), gender, and age. No patients with alpha 1-antitrypsin deficiency, homocystinuria, or diagnosed collagen or connective tissue disease were included. All subjects responded to a questionnaire regarding history of pneumothorax, and smoking habits, and were also questioned during hospital visits. A written informed consent was obtained from all subjects for molecular and clinical testing.

\subsection{Genotyping of the MMP-9 Gene}

Five-millilitre blood samples were drawn from each subject in an ethylene diamine tetraacetic acid-containing vacutainer tube and stored at $4{ }^{\circ} \mathrm{C}$. Genomic DNA was extracted from blood within one week after sampling. The blood was diluted with an equal volume of $0.9 \%(\mathrm{w} / \mathrm{v}) \mathrm{NaC} 1$, layered onto a cushion of Ficoll-Hypaque $(1.077 \mathrm{~g} / \mathrm{mL})$ and centrifuged at room temperature for $30 \mathrm{~min}$ at $400 \mathrm{x}$ g. The mono-nuclear cells were collected from the interface and washed twice with $20 \mathrm{mM}$ phosphate buffer, $\mathrm{pH} 7.4$, containing $138 \mathrm{mM} \mathrm{NaC1}$ and $2.7 \mathrm{mM}$ $\mathrm{KC} 1$ (PBS).

The genomic DNA was extracted from the mononuclear cells of each participant, using MasterPure ${ }^{\mathrm{TM}}$ DNA Purification Kit for Blood Version II (epicenter an Illumina company), and stored at $-20{ }^{\circ} \mathrm{C}$ until genotypic analysis was done. Before storage the DNA was quantitated by spectrophotometry at $260 \mathrm{~nm}$ in a Biochrom 4060 (Pharmacia/LKB), and the concentration was approximately $200-500 \mu \mathrm{g} / \mathrm{mL}$.

The specific genotypes of the MMP-9 promoter identified using a polymerase chain reaction followed by restriction fragment length polymorphism analysis (PCR-RFLP). For an analysis of the $-1562 \mathrm{C}>\mathrm{T}$ polymorphism in the MMP-9 promoter, PCR was performed using primer pairs designed to amplify the sequence from 1809 to 1374 in the promoter region. The sequences of the sense and antisense oligonucleotide primers were 5'-GCCTGGCACATAGTAGGCCC-3' and 5'-CTTCCTAGCCAGCCGGCATC-3', respectively.

The PCR reactions were performed in a $25 \mu \mathrm{L}$ volume containing $100 \mathrm{ng}$ of DNA template, $2.5 \mu \mathrm{L}$ of 10× PCR buffer, $1.5 \mathrm{mM}$ of $\mathrm{MgCl}, 1 \mathrm{U}$ of Taq-DNA-polymerase (BioDev-Tech), $200 \mu \mathrm{M}$ of dNTPs and $200 \mathrm{nM}$ of forward and reverse primer. The 
PCR cycling conditions were $5 \mathrm{~min}$ at $94{ }^{\circ} \mathrm{C}$ followed by 35 cycles of $30 \mathrm{~s}$ at $94{ }^{\circ} \mathrm{C}, 30 \mathrm{~s}$ at $57^{\circ} \mathrm{C}$ and $30 \mathrm{~s}$ at $72{ }^{\circ} \mathrm{C}$, with a final step at $72{ }^{\circ} \mathrm{C}$ for 5 min to allow for the complete extension of all PCR fragments.

$8 \mu \mathrm{l}$ aliquot of the resulting $435 \mathrm{bp}$ amplification product was digested overnight at $37{ }^{\circ} \mathrm{C}$ in a $10 \mu \mathrm{l}$ reaction containing $10 \mathrm{U}$ of SphI enzyme (TakaRa Biotechnology Co. Ltd). After overnight digestion, the products were subjected to electrophoresis on a $2 \%$ agarose gel, and stained with ethidium bromide. This resulted in three potential fragments $(435,247$ and 188 bp in size). The MMP-9 - $1562 \mathrm{~T}$ allele is digested by SphI, yielding fragments of 247 and $188 \mathrm{bp}$ while the $-1562 \mathrm{C}$ allele is not cleaved by SphI and keeps the original PCR product (435 bp), the CT heterozygotes showed the three bands (435, 247 and $188 \mathrm{bp})$.

For a negative control, distilled water was used instead of DNA in the reaction system for each panel of PCR.

\section{Statistical Analysis}

Statistical analysis was performed using SPSS10.0 software package (SPSS Company, Chicago, IL, USA). All polymorphisms were tested for confirmation with Hardy-Weinberg expectations in both groups separately using the chi square test. The cases and controls were compared chi-squared test for categorical variables. Comparison of the MMP-9 genotype distribution in the study groups was performed by using the chi-square test. The odds ratio (OR) and 95\% confidence interval (CI) were calculated using an unconditional logistic regression model. A probability level less than 5\% was considered significant.

\section{Results}

A sample of 104 PSP patients and 97 age-matched healthy control subjects participated in our study. The baseline characteristics of the subjects are presented in table 1. All subjects were genotyped for the MMP-9 promoter (C-1562T) polymorphism by restriction enzyme digestion (Fig. 1). The distributions of genotypes were consistent with Hardy-Weinberg equilibrium.

As shown in table 2, there were no TT homozygotes in the control group, and one appeared in the PSP group, also the table shows that the genotype frequency for MMP-9 $1562 \mathrm{C}>\mathrm{T}$ differed significantly between healthy individuals and PSP patients $(P=0.007)$. The variant allele frequency was significantly different between healthy individuals and PSP cases $(P=0.023)$, the frequencies of the T allele in the MMP-9 promoter were 9.62 and $2.06 \%$ in the PSP and control groups, respectively as shown in table 3 .

The prevalence of $\mathrm{C} / \mathrm{C}$ allele for MMP-9 $1562 \mathrm{C}>\mathrm{T}$ was higher in controls compared to PSP patients, showing protective association with PSP development (OR $=0.192,95 \% \mathrm{CI}=0.06-0.59, P=0.003)$. On the other hand, the $\mathrm{C} / \mathrm{T}+\mathrm{T} / \mathrm{T}$ genotypes significantly modified the risk of developing PSP and, the odds ratios were 5.197 (95\% CI = 1.70-15.89) (Table 4).

\section{Discussion}

A primary spontaneous pneumothorax occurs when air collects in the pleural space without preceding trauma in a healthy individual, and without obvious underlying lung disease. [19]. However, in a study done by Ayed et al [20], it was found that all patients with PSP had microscopic evidence of underlying lung disease when their excised apices of lung were examined. Other studies showed that these lesions were the result of a degenerative process of the

Table 1 Baseline characterestics of patients in the two groups.

\begin{tabular}{lll}
\hline & PSP & Controls \\
\hline Number of cases & 104 & 97 \\
Male/Female & $102 / 2$ & $97 / 0$ \\
Age (years) ( \pm SD) & $30 \pm 11$ & $32 \pm 8$ \\
Smokers/Non smokers & $95 / 9$ & $89 / 8$ \\
Number of cigarettes consumed/day ( \pm SD) & $20 \pm 12$ & $23 \pm 10$ \\
Recurrence & 14 & - \\
\hline
\end{tabular}




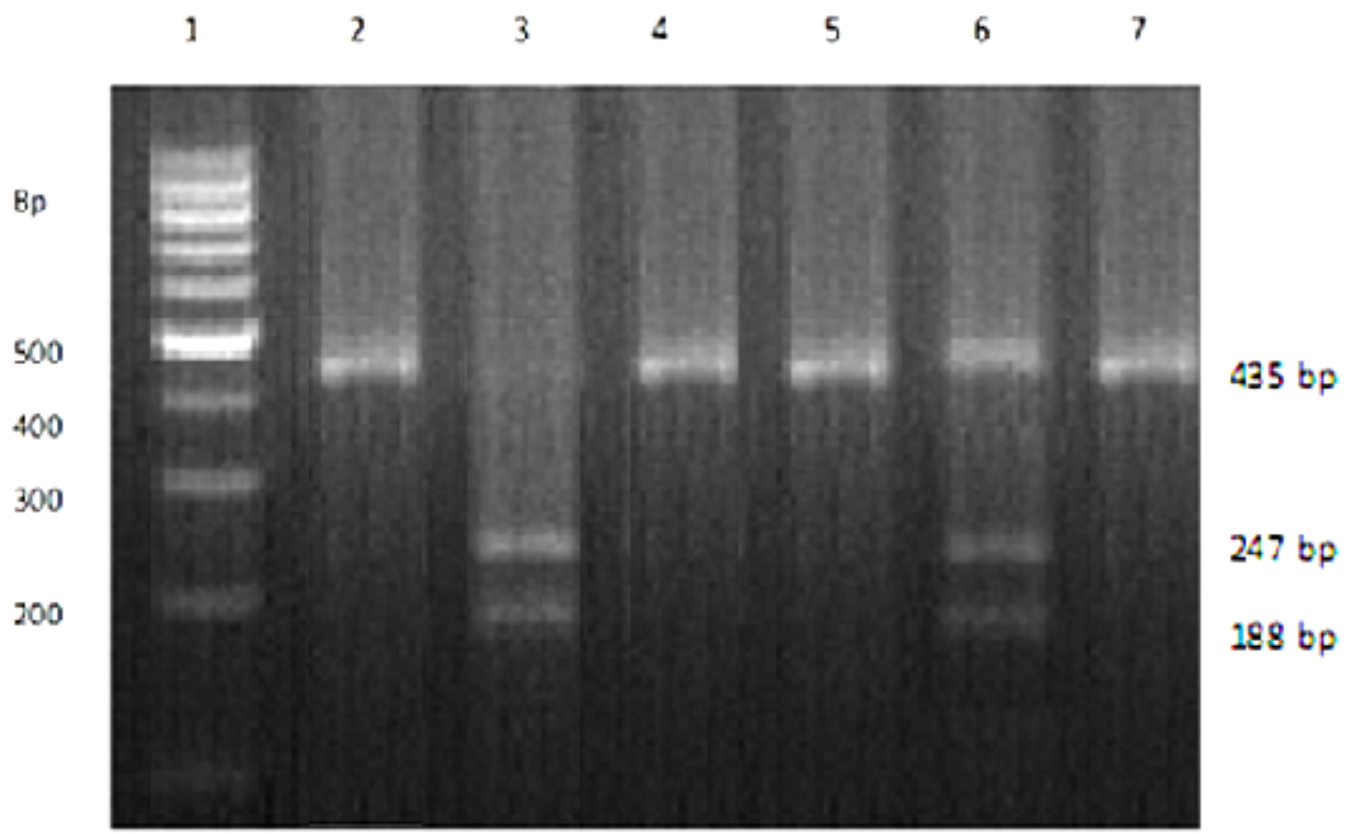

Fig. 1 MMP-9 genotyping by PCR-RFLP analysis followed by separation on 2\% agarose gel. Lane 1, 100 bp ladder; lanes 2, 4, 5 and $7, C / C$; lane $3, T / T$; lane $6, \mathrm{C} / \mathrm{T}$.

Table 2 The distribution of genotypes in the promoter of MMP-9 (-1562 C/T) between the two groups.

\begin{tabular}{llllll}
\hline \multirow{2}{*}{ Group } & \multirow{n}{*}{} & \multicolumn{4}{c}{ Genotype (\%) } \\
\cline { 3 - 6 } & & $\mathrm{C} / \mathrm{C}$ & $\mathrm{C} / \mathrm{T}$ & $\mathrm{T} / \mathrm{T}$ & $0(0.00)$ \\
\hline Controls & 97 & $93(95.88)$ & $4(4.12)$ & $10.007^{*}$ \\
PSP & 104 & $85(81.73)$ & $18(17.31)$ & $1(0.96)$ & \multirow{2}{*}{} \\
\hline
\end{tabular}

*Indicates statistically significant difference.

$\mathrm{PSP}=$ Primary spontaneous pneumothorax.

Table 3 The distribution of allele genes in the promoter of MMP-9 (-1562 C/T) between the two groups.

\begin{tabular}{|c|c|c|c|c|}
\hline \multirow{2}{*}{ Group } & \multirow{2}{*}{$\mathrm{n}$} & \multicolumn{2}{|c|}{ Alleles (\%) } & \multirow{2}{*}{$P$ value } \\
\hline & & $\mathrm{C}$ & $\mathrm{T}$ & \\
\hline Controls & 97 & $190(97.94)$ & $4(2.06)$ & \multirow{2}{*}{$0.023^{*}$} \\
\hline PSP & 104 & $188(90.38)$ & $20(9.62)$ & \\
\hline
\end{tabular}

* Indicates statistically significant difference.

PSP=Primary spontaneous pneumothorax.

Table 4 Association of the single nucleotide polymorphism with the risk of development of PSP.

\begin{tabular}{llll}
\hline Genotype & OR & $95 \%$ CI & $P$ value \\
\hline $\mathrm{C} / \mathrm{C}$ & 0.192 & $0.06-0.59$ & $0.003^{*}$ \\
$\mathrm{C} / \mathrm{T}+\mathrm{T} / \mathrm{T}$ & 5.197 & $1.70-15.89$ & $0.003^{*}$ \\
\hline
\end{tabular}

* Indicates statistically significant difference.

lung, and were considered as a form of distal acinar emphysema [21, 22].

The primary mechanism of lung parenchymal destruction in emphysema is believed to be an imbalance between endogenous proteinases and antiproteinases. MMP-9 is a member of a family of proteinases, its significant biological function, which is related to destruction of lung parenchyma, is considered to be due to its proteolytic effect on substrates such as extracellular matrix proteins and 
antiproteinases [23]. The role of MMP-9 has been shown to be important in the development of emphysema in animal [24] and human [25, 26].

Recently, Zhang et al [27] reported a novel polymorphism $(-1562 \mathrm{C}>\mathrm{T})$ in the promoter region of the MMP-9. The promoter region contains an important regulatory element of gene expression, to which a transcription repressor protein binds. The DNA-protein interaction is lost due to a $\mathrm{C}$ to $\mathrm{T}$ substitution at the polymorphism site. This results in a promoter, with higher promoter activity, and an increased level of MMP-9 synthesis, which may be because of the preferential binding of a putative transcription repressor protein to the $\mathrm{C}$ allelic promoter [28]. This finding can explain our results which showed that the genotype frequency for MMP-9 1562 $\mathrm{C}>\mathrm{T}$ differed significantly between healthy individuals and PSP patients, with higher $\mathrm{T}$ allele in the MMP-9 promoter in PSP patients, which means higher promoter activity and increased level of MMP-9. Excess MMP-9 may contribute to the immunopathology that leads to aberrant turnover of the ECM [29].

These findings are in agreement with the results of a previous study done by Steagall WK et al [30] that showed that polymorphism in the MMP-1 gene that results from insertion of a guanine into the promoter, creates a binding site for ETS transcription factor [31]. Consequently the $2 \mathrm{G}$ form of the promoter produced higher transcriptional activity than the $1 \mathrm{G}$ form, and was associated with pneumothorax [32].

To the best of our knowledge, this is the first study to look for an association between polymorphisms of MMP-9 $(-1562 \mathrm{C}>\mathrm{T})$ and the development of PSP.

Our data showed that $\mathrm{C} / \mathrm{T}+\mathrm{T} / \mathrm{T}$ genotypes significantly modified the risk of developing PSP, and were associated with increased risk for PSP. On the other hand $\mathrm{C} / \mathrm{C}$ allele for MMP-9 $1562 \mathrm{C}>\mathrm{T}$ showed a protective association with PSP development. These findings suggest that there may be a genetic predisposition to primary spontaneous pneumothorax, and it is possible that an increase in MMP-9 (resulting from the SNP in its promoter) leads to more degradation of the ECM and increased risk of pneumothorax [30].

In conclusion, this study showed that MMP-9-1562 $\mathrm{C} / \mathrm{T}$ genotype may be a potentially indicative factor for susceptibility to PSP, that is, genotypes with the T allele significantly increase the risk of development of PSP.

Further studies on a larger population will be required for better understanding of the physiological and pathological roles of MMPs in the development of PSP, and to confirm the role of MMP-9 C-1562 T polymorphism in disease development and progression. Also the potential role of MMP inhibitors as a treatment for cases of PSP should be further investigated.

\section{References}

[1] Gupta, D., Hansell, A., Nichols, T., Duong, T., Ayres, J. G., and Strachan, D. 2000. "Epidemiology of Pneumothorax in England." Thorax 55: 666-71.

[2] Sahn, S. A., and Heffner, J. E. 2000. "Spontaneous Pneumothorax." N. Engl. J. Med. 342: 868-74.

[3] Henry, M., Arnold, T., and Harvey, J. 2003. "BTS Guidelines for the Management of Spontaneous Pneumothorax.” Thorax 58 (Suppl. 2): 39-52.

[4] Jordan, K. G., Kwong, J. S., Flint, J., and Müller, N. L. 1997. "Surgically Treated Pneumothorax. Radiologic and Pathologic Findings." Chest 111: 280-5.

[5] Baronofsky, I. D., Warden, H. G., Kaufman, J. L., Whatley, J., and Hanner, J. M. 1957. "Bilateral Therapy for Unilateral Spontaneous Pneumothorax." J. Thorac. Cardiovasc. Surg. 34: 1767-9.

[6] Ikeda, M., Uno, A., Yamane, Y., and Hagiwara, N. 1988. "Median Sternotomy with Bilateral Bullous Resection for Unilateral Spontaneous Pneumothorax, with Special Reference to Operative Indications." J. Thorac. Cardiovasc. Surg. 96: 615-20.

[7] Fukuda, Y., Haraguchi, S., Tanaka, S., and Yamanaka, N. 1994. "Pathogenesis of Blebs and Bullae of Patients with Spontaneous Pneumothorax: Ultrastructural and Immunohistochemical Studies.” Am. J. Respir. Crit. Care. Med. 149: A1022.

[8] Tetely, T. D. 1993. "Proteinase Imbalance: Its Role in Lung Disease." Thorax 48: 560-5.

[9] Rodriguez, D., Morrison, C. J., and Overall, C. M. 2010. 
"Matrix Metalloproteinases: What Do They Not Do? New Substrates and Biological Roles Identified by Murine Models and Proteomics." Biochim Biophys Acta 1803: $39-54$.

[10] Atkinson, J. J., and Senior, R. M. 2003. "Matrix Metalloproteinase-9 in Lung Remodeling." Am. J. R. espir. Cell. Mol. B. iol. 28: 12-24.

[11] Zhang, B., Henney, A., Eriksson, P., Hamsten, A., Watkins, H., and Ye, S. 1999. "Genetic Variation at the Matrix Metalloproteinase-9 Locus on Chromosome 20q12.2-13.1." Hum. G. enet. 105: 418-23.

[12] Hirakawa, S., Lange, E. M., Colicigno, C. J., Freedman, B. I., Rich, S. S., and Bowden, D. W. 2003. "Evaluation of Genetic Variation and Association in the Matrix Metalloproteinase 9 (Mmp9) Gene in ESRD Patients." Am. J. K. idney. Dis. 42: 133-42.

[13] Zhang, B., Ye, S., Herrmann, S. M., Eriksson, P., de Maat, M., Evans, A., Arveiler, D., Luc, G., Cambien, F., and Hamsten, A. 1999, et al. "Functional Polymorphism in the Regulatory Region of Gelatinase B Gene in Relation to Severity of Coronary Atherosclerosis." Circulation 99: 1788-94.

[14] Blankenberg, S., Rupprecht, H. J., Poirier, O., Bickel, C., Smieja, M., Hafner, G., Meyer, J., Cambien, F., Tiret, L.; AtheroGene Investigators 2003. "Plasma Concentrations and Genetic Variation of Matrix Metalloproteinase 9 and Prognosis of Patients with Cardiovascular Disease." Circula-tion 107: 1579-85.

[15] Minematsu, N., Nakamura, H., Tateno, H., Nakajima, T., and Yamaguchi, K. 2001. "Genetic Polymorphism in Matrix Metalloproteinase-9 and Pulmonary Emphysema." Biochem Biophys Res Commun 289: 116-9.

[16] Joos, L., He, J. Q., Shepherdson, M. B., Connett, J. E., Anthonisen, N. R., Pare, P. D., and Sandford, A. J. 2002. "The Role of Matrix Metalloproteinase Polymorphisms in the Rate of Decline in Lung Function.” Hum Mol Genet 11: 569-76.

[17] Zhou, M., Huang, S. G., Wan, H. Y., Li, B., Deng, W. W., and Li, M. 2004. "Genetic Polymorphism in Matrix Metalloproteinase-9 and the Susceptibility to Chronic Obstructive Pulmonary Disease in Han Population of South China." Chin. Med. J. (Engl) 117: 1481-4.

[18] Ito, I., Nagai, S., Handa, T., Muro, S., Hirai, T., Tsukino, M., and Mishima, M. 2005. "Matrix Metalloproteinase-9 Promoter Polymorphism Associated with Upper Lung Dominant Emphysema." Am. J. Respir. Crit. Care Med. 172 (11): 1378-82.

[19] Light, R. W. 1993. "Man Agement of Spontan Eous Pneumoth Orax." Am. Rev. Respir. Dis. 148: 245-8.

[20] Ayed, A., Chandrasekaran, C., and Sukumar, A. 2006. "Video-assisted Thoracoscopic Surgery for Primary
Spontaneous Pneumothorax: Clinicopathological Correlation." European Journal Cardio-Thoracic Surgery 29: 221-5.

[21] Janssen, J. P., Schramel, F. M. N. H., Sutedja, T. G., Cuesta, M. A., and Postmus, P. E. 1995. "Videothoracoscopic Appearance of First and Recurrent Pneumothorax." Chest 108: 330-4.

[22] Migliore, M., Maria, G. Di, Criscione, A., and Rassl, D. 2013. "Clinico-pathological Findings in Stage-I Primary Spontaneous Pneumothorax: Analysis of 19 Cases and Literature Review.” European Surgery 45 (2): 83-6.

[23] Finlay, G. A., O’Driscoll, L. R., Russell, K. J., D’Arcy, E. M., Masterson, J. B., FitzGerald, M. X., and O'Connor, C. M. 1997. "Matrix Metalloproteinase Expression and Production by Alveolar Macrophages in Emphysema." Am. J. Respir. Crit. Care Med. 156: 240-7.

[24] Choe, K. H., Taraseviciene-Stewart, L., Scerbavicius, R., Gera, L., Tuder, R. M., and Voelkel, N. F. 2003. "Methylprednisolone Causes Matrix Metalloproteinase Dependent Emphysema in Adult Rats." Am. J. Respir. Crit. Care Med. 167: 1516-21.

[25] Russell, R. E., Thorley, A., Culpitt, S. V., Dodd, S., Donnelly, L. E., Demattos, C., Fitzgerald, M., and Barnes, P. J. 2002. "Alveolar Macrophage-mediated Elastolysis: Roles of Matrix Metalloproteinases, Cysteine, and Serine Proteases.” Am. J. Physiol Lung Cell Mol. Physiol 283: L867-73.

[26] Montano, M., Beccerril, C., Ruiz, V., Ramos, C., Sansores, R. H., and GonzalezAvila, G. 2004. "Matrix Metalloproteinases Activity in COPD Associated with Wood smoke." Chest 125: 466-72.

[27] Zhang, B., Ye, S., and Herrmann, S. M. 1999, et al. "Functional Polymorphism in the Regulatory Region of Gelatinase B Gene in the Relation to Severity of Coronary Atherosclerosis." Circulation 99: 1788-94.

[28] Pollanen, P. J., Karhunen, P. J., Mikkelsson, J., Laippala, P., Perola, M., Penttila, A., Mattila, K. M., Koivula, T., and Lehtimaki, T. 2001. "Coronary Artery Complicated Lesion Area is Related to Functional Polymorphism of Matrix Metalloproteinase 9 Gene: An Autopsy Study." Arterioscler. Thromb. Vasc. Biol. 21: 1446-50.

[29] Elkington, P. T., and Friedland, J. S. 2006. "Matrix Metalloproteinases in Destructive Pulmonary Pathology." Thorax 61: 259-66.

[30] Steagall, W. K., Glasgow, C. G., Hathaway, O. M., Avila, N. A., Moss, A. M., Taveira-DaSilva, A. M., Rabel, A., Stylianou, M. P., Lin, J. P., Chen, X., and Moss, J. 2007. "Genetic and Morphologic Determinants of Pneumothorax in Lymphangioleiomyomatosis." Am. J. Physiol Lung Cell Mol. Physiol 293: L800-8. 
[31] Tower, G. B., Coon, C. I., and Brinckerhoff, C. E. 2003. "The $2 \mathrm{G}$ Single Nucleotide Polymorphism (SNP) in the MMP-1 Promoter Contributes to High Levels of MMP-1 Transcription in MCF-7/ADR Breast Cancer Cells." Breast Cancer Res. Treat 82: 75-82.

[32] Matrix Metalloproteinase-9 Promoter Polymorphism
Associated with Upper Lung Dominant Emphysema Isao Ito, Sonoko Nagai, Tomohiro Handa, Shigeo Muro, Toyohiro Hirai, Mitsuhiro Tsukino, and Michiaki Mishima Am. J. Respir. Crit. Care Med. Vol. 172. pp 1378-1382, 2005. Originally Published in Press as DOI: 10.1164/rccm.200506-953OC. 